\title{
A reflection on continuing professional development
}

\author{
Kieran O'Loughlin, ${ }^{1}$ Allys Guerandel, ${ }^{1}$ Kevin Malone ${ }^{1}$
}

The Psychiatrist (2012), 36, 189-193, doi: 10.1192/pb.bp.111.035717

${ }^{1}$ St Vincent's University Hospital, Dublin

Correspondence to Kieran O'Loughlin (oloughlk@hotmail.com)

First received 18 Jun 2011, final revision 30 Sep 2011, accepted 2 Dec 2011
Summary The enactment of Part II of the Medical Practitioners Act 2007 in Ireland heralds a move from voluntary to statutory provision of professional competence and marks an important advance in medical professionalism in the country. This formalises consultant psychiatrists' existing commitment to updating their knowledge and skills and compels basic and higher specialist trainees to actively engage in the process. The relevance of reflective practice for professional and personal development of trainee psychiatrists is discussed and the role of existing trainee learning activities in the process of lifelong learning is explored in this context.

Declaration of interest None.

The Irish Medical Practitioners Act 2007 has given formal recognition to the need for clinicians in Ireland to maintain and develop the knowledge, skills and attitudes relevant to their professional work. ${ }^{1}$ The Act represents an attempt by the Irish Medical Council to move away from the traditional model of continuing professional development (CPD), which was a generic, unstructured point-gathering exercise. This is undoubtedly a necessary and timely move. In its handbook Professional Competence for Psychiatrists, the College of Psychiatry of Ireland makes reference to a number of educational initiatives that can be undertaken by a consultant psychiatrist to contribute to CPD. ${ }^{2}$ Under the new Act, all non-consultant hospital doctors working in psychiatry will also be required to undertake their own formalised programme of CPD. A model of CPD that is broadly similar from postgraduate training through higher specialist training to consultancy is surely desirable and gives credence to the word 'continuing'.

But can a model of CPD for senior clinicians be tailored to the needs of junior trainees? The educational activities that can be undertaken and contribute to consultant CPD can appear to the trainee as quite disparate and in some instances irrelevant for progression to higher specialist training and on to consultancy. If CPD activities lack personal relevance, then maintaining trainee motivation for engagement in such a context may be difficult. Making such activities compulsory (as is the case with enforcement of Part II of the Irish Medical Practitioners Act) will facilitate trainee participation but is unlikely to be an adequate solution to the problem, since learning that is based on avoiding negative consequences will likely be superficial and short-lived. $^{3}$ Additionally, professional development is a complex process, and although elements of CPD such as case conferences, journal clubs and clinical audit may promote professionalism and inform practice, they are not likely to be sufficient to do so. Establishing an evidence base that can be used to govern practice through such activities is paramount, but this 'scientist-practitioner' model is insufficient to inform what Schön referred to as the 'indeterminate zones of practice ${ }^{4}$ - those characterised by unexpectedness and value conflicts giving rise to the moment-by-moment decisions on the wards, in the emergency department and in the out-patient clinic. The challenge for the new College of Psychiatry of Ireland and its postgraduate training pillar is to establish a culture in which trainees take on the responsibility for their personal development. Trainees need to be encouraged to manage their own professional growth by developing a broad range of skills and competencies in their own work and personal environments and to integrate these with the established evidence base derived from CPD activities.

So how can this challenge be met? In the interim report, the College of Psychiatry of Ireland defines competence assurance as the continuation of education from undergraduate level through postgraduate to retirement'. ${ }^{2}$ Additionally, in its 2007 review of medical schools in Ireland, the Medical Council refers to the encouragement of reflective practice processes as one of the key indicators of good practice, implying that a model of competence assurance and CPD at postgraduate level that is rooted in the reflective processes fostered at undergraduate level has relevance. ${ }^{5}$ In line with these recommendations, the teaching and assessment of reflection in psychiatry has already been introduced at the undergraduate level in Ireland. ${ }^{6}$ The postgraduate curriculum has yet to follow suit.

\section{What is reflective practice?}

An understanding of the term 'reflective practice' can be gleaned by first examining the concept of 'reflection'. Reflection can be considered a process whereby thoughts 


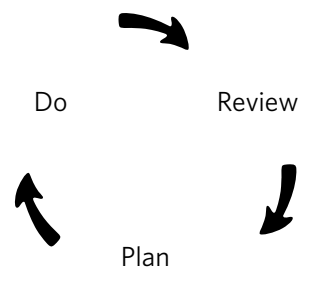

Fig 1 Three-stage model of reflection.

are analysed (usually in relation to particular events or situations), leading to a greater awareness. Such awareness can then be used when encountering similar situations or events in the future. A simple three-stage model is often used to represent the process of reflection (Fig. 1).

Table 1 outlines a number of definitions of reflection that make reference to the active nature of the reflective process as it incorporates thought and action.

The definition proposed by Sandars (Table 1) emphasises the continuous nature of reflection and the meta-cognitive process ('thinking about thinking') at the heart of reflection. ${ }^{9}$

Moon provides a useful overview of reflection and a framework for the consideration of reflection in learning and professional development. ${ }^{10}$ She sees reflection as a way of thinking, whereby we actively review issues that affect us. This process results in a deeper understanding or a new perspective reached by analysing our existing knowledge, attitudes and feelings regarding an event. Her model draws on the learning cycle, developed by Kolb. ${ }^{11}$ In Kolb's fourstage cycle (Fig. 2), the individual reflects on experience and draws theoretical conclusions, which can then be used to influence future action. In this way, reflection, theory and action are linked. If one is to learn from the experience, it must be integrated with existing knowledge, attitudes and emotions/feelings, thus becoming a new experience.

The term 'reflective practice' was initially used by Schön. ${ }^{412}$ At the root of Schön's work was an attempt to outline how professional knowledge is unlike the kinds of knowledge presented in textbooks, scientific papers and academic journals. Schön noted that clinicians often have to

\begin{tabular}{|c|c|}
\hline Source & Definition \\
\hline $\begin{array}{l}\text { Dewey } \\
(1938)^{7}\end{array}$ & $\begin{array}{l}\text { 'An active, persistent and careful consideration } \\
\text { of any belief or supposed form of knowledge } \\
\text { in light of the grounds that support it and } \\
\text { the further conclusions to which it tends' }\end{array}$ \\
\hline $\begin{array}{l}\text { Boud et al } \\
(1985)^{8}\end{array}$ & $\begin{array}{l}\text { 'A generic term for those intellectual and } \\
\text { affective activities in which individuals engage } \\
\text { to explore their experiences in order to lead } \\
\text { to a new understanding and appreciation' }\end{array}$ \\
\hline $\begin{array}{l}\text { Sandars } \\
(2009)^{9}\end{array}$ & $\begin{array}{l}\text { 'A meta-cognitive process that occurs before } \\
\text { during and after situations with the purpose } \\
\text { of developing a greater understanding of both } \\
\text { the self and the situation so that future } \\
\text { encounters with the situation are informed } \\
\text { by previous encounters' }\end{array}$ \\
\hline
\end{tabular}

Fig 2 Kolb's four-stage cycle of reflection.

respond to a wide variety of poorly defined complex situations. The primary reason for consciously and systematically engaging with the process of reflection in these contexts is to consider the degree to which the influences from our past overlap with the requirements of whatever clinical situation we now face.

A reflective practice model of $\mathrm{CPD}$ implies that psychiatrists are actively involved in their own personal and professional development, critically analysing their clinical environment, evaluating their decision-making and drawing on this insight to help identify which activities are likely to be of most benefit in addressing personal deficits in knowledge or competence. The planning phase of Kolb's four-stage cycle is the phase in which the clinician should identify and engage in relevant CPD activities.

\section{Putting reflection into practice}

It is useful to identify the processes involved in reflective practice:

- reflection-in-action and reflection-on-action

- reflection about impact on others

- self-reflection.

There is overlap between these concepts, but when they are considered in the context of CPD activities in psychiatry there is rationale and precedent ${ }^{13}$ for distinguishing them.

\section{Reflection-in-action and reflection-on-action}

Schön refers to processes that are fundamental to, but often unrecognised in, all professional practice - reflectionin-action and reflection-on-action. ${ }^{4}$ Such processes are often precipitated by confrontation with the unexpected, where theory derived from textbooks, journals or formal teaching is insufficient to determine the best course of action. Reflection-in-action is the process of reflecting (both cognitively and emotionally) on what you are doing, while you are doing it, with a view to determining the next best course of action. ${ }^{4}$ Analysis of the context of the event, incorporating our own subjectivity, influences our decisionmaking. Schön states that it is our ability to reflect critically in these moments of uncertainty and complexity that lies at the core of professional practice and development. 
Reflection-on-action refers to a process of contemplation after the event, with the purpose of informing future action in a similar context.

\section{Reflection about impact on others}

It is the interactions with patients and colleagues into which we bring our own experiences, attitudes and ways of relating. With the transition from the medical to the biopsychosocial model of patient care in psychiatry, and the development of multidisciplinary teams, the ability of the trainee to engage in the process of reflection about impact on others is now more important than ever. A move away from the paternalism at the heart of the old medical model means that the effective psychiatrist is increasingly becoming one who can work collaboratively with others on agreed patient-centred goals. In this context, the trainee's awareness of their skills and, more importantly, their limitations is essential to an effective team dynamic. In a similar way, recognising and using the expertise of colleagues where appropriate, and equally recognising and accepting their limitations, is essential to effective team functioning. An effective multidisciplinary team is one in which there is an open atmosphere, criticism is frank, members are free to express their feelings, and team effectiveness (measured by patient-centred outcomes) is reviewed regularly. An awareness of how interaction on a professional and personal level with team members has an impact on team functioning and patient care is essential. Is there conflict between team members? What has led to this? What is the impact of it? How can it be overcome? Recognising the origins of the problem through active reflection with a view to conflict resolution is a skill of leadership that all trainees need to foster. The trainee, as a member of the multidisciplinary team, must demonstrate an ability to reflect on their impact on colleagues.

\section{Self-reflection}

Self-reflection should be at the core of clinical practice for psychiatric trainees, particularly given the expectations that are often placed on patients themselves to engage in this process. Self-reflection can help a trainee identify their own vulnerabilities and how these may impact on patient care. A return to the clinical environment after linking these processes to a relevant $\mathrm{CPD}$ activity is essential to determine impact on practice. Clinical encounters with challenging patients are the norm for a postgraduate trainee in psychiatry. In many of these situations the trainee may perceive an ethical or moral dilemma (e.g. dealing with sensitive issues in the context of patient confidentiality). Such situations may precipitate unexpected emotional responses from the trainee, responses that may be influenced by the trainee's own values and attitudes. Self-reflection can be incorporated into the trainee's decision-making process. Noting and recording these internal processes alone or in consultation with senior colleagues or a peer group can help the trainee to reflect on and make sense of their experience and decision-making process.

\section{Enabling trainee reflection}

There are myriad clinical encounters, from encountering patients with deficits in communication skills to dealing with a patient's suicide, that may initiate a CPD cycle for the psychiatric trainee. Essential to linking clinical experience to CPD activities are one or more of the aforementioned processes of reflection. In enabling such reflection, the following can provide guidance for the trainee.

\section{Clinical supervision}

Clinical supervision should be considered not only a formal process of professional support but also a potentially powerful teaching tool facilitating professional development through reflection-on-action and self-reflection, meeting the CPD needs of both the trainee and the supervisor. The supervisor can help the trainee to reflect on a clinical encounter, reviewing what has been done, what evidence from the literature is relevant, or whether a situation takes the supervisor, the trainee or both beyond existing theory. In line with the reflective model, generating plans about the next step in the process should form a part of this practice. Clinical supervision record sheets should be used to record key headings and topics and actions to air reflection. Supervision should be frequent enough to be meaningful, be of sufficient duration to allow for in-depth reflection, and be properly structured to achieve these aims.

\section{Peer supervision and peer review}

Peer review groups are small, self-selected groups of peers who meet to promote reflective practice. An atmosphere of openness, frankness and mutual support is vital to the functioning of these groups, which should be non-judgemental and constructive in their ethos. ${ }^{14}$ One aspect of the term peer is that power relationships remain flat. In contrast to the hierarchical nature of clinical supervision, peer-review groups may allow trainees to be more forthcoming with attitudes relevant to the reflective process, enabling in particular reflection about impact on others. A pilot peer-review group initiative for consultant psychiatrists is ongoing in Ireland. ${ }^{14}$ The College of Psychiatry of Ireland has issued guidelines regarding the proposed structure of such groups. ${ }^{15}$ Extending this initiative to trainee psychiatrists could greatly enhance the reflective potential of trainee CPD.

\section{Online discussion boards}

Developments in information and communications technology mean that asynchronous technologies such as blogs and discussion boards are increasingly being used to facilitate peer interaction in educational settings. ${ }^{16}$ These present the advantage of encouraging shyer trainees and less fluent English speakers to reflect on relevant clinical issues and allow time for reflection before posting. Such technology can also be used to link trainees to relevant websites and articles in electronic journals that may inform the reflective process. At individual training sites, discussion boards could be used to generate further peer interaction on points of interest arising from case conferences and journal clubs, thus linking effectively to other CPD elements. 


\section{Reflective diaries}

Time constraints that may make frequent formal reflection difficult could be facilitated by diary entries that allow deeper reflection where time permits and as skills develop over the course of a clinical attachment. Adhering to the reflective cycle (Fig. 2), with an emphasis on the outcomes of reflective entries as well as the reflections themselves, is important if professional development is to occur. Diary entries should be collated and used as a reflective portfolio linking all aspects of reflective practice for the trainee.

\section{Traditional CPD activities}

The following traditional CPD activities, if undertaken in a judicious manner by the trainee, have the potential to both enable the process of trainee reflection and address deficits in trainee knowledge or competency.

\section{Case conferences and journal clubs}

In postgraduate training schemes, case presentations occurring every 1-2 weeks are the most frequently used teaching and learning activity, allowing consultant psychiatrists to acquire CPD points. Case conferences are useful for presenting cases where there is a diagnostic or treatment dilemma. If a diagnostic or treatment decision has not been reached, the opportunity for reflection-onaction is even greater. Incorporating a patient interview into the case conference and requiring trainees as individuals or in small groups (facilitated or not) to examine the processes of thinking and feeling during their presentation and interview can prove constructive and develop their skills in this regard.

Journal clubs have traditionally been valued as a means of keeping abreast of the literature. With the explosion in the number of medical journals, this goal has become somewhat unrealistic, and the emphasis has changed for most journal clubs to promoting evidence-based practice and teaching critical appraisal. Linking the journal topic of interest demonstrably to the diagnostic or treatment dilemma presented in a case conference could benefit the reflective process significantly. Certain components of the critical appraisal process lend themselves well to reflection: for example, can the conclusions or recommendations of a journal article be extrapolated to the problem at hand? If not, why not? Are there divergent opinions among those present, and what are the influences on these opinions?

\section{Balint groups}

In Ireland, attending 30 sessions of a Balint group (a form of case-based discussions) was a mandatory requirement for basic specialist training in psychiatry in the old curriculum. $^{17,18}$ The place of these groups in the new curriculum is unclear. They could be integrated into a model of reflective practice CPD. Balint groups are usually small, with the number of participants ranging from 6 to 12 . The purpose of these groups, as outlined by Samuel, aligns well with the concepts of reflection-on-action, reflection about impact on others and self-reflection. ${ }^{19}$ Samuel identifies the aims and objectives of Balint training as follows:
- to encourage doctors to value their interpersonal skills and to learn to understand their limits

- to improve doctors' perceptions and understanding of their patients' communication

- to allow doctors to become aware of their blind spots in their interaction with patients.

\section{Clinical audit}

Clinical audit, the process in which trainees reflect on and improve their and the team's clinical practice, is fundamental to improving the quality of care received by patients. The Irish Medical Council has stipulated that all registered medical practitioners must be actively engaged in audit and, at a minimum, participate in one audit exercise annually that relates directly to their practice. ${ }^{20}$ Many trainees face difficulty completing the audit cycle, partly due to time limitations in a particular training post but perhaps also as a consequence of poor motivation due to perceived lack of personal relevance. An audit cycle informed by the trainee's own reflections and incorporated into a reflective practice model of CPD would have a greater chance of completion.

\section{Assessment of reflective practice}

Workplace-based assessments will shortly become a mandatory requirement for basic specialist trainees in Ireland. These assessments are already in extensive use in the UK and facilitate the assessment of a range of practical and communication skills. They allow for immediate trainee feedback requiring both trainee and trainer to discuss development needs as part of the process of assessment. The potential for reflection-in-action and reflection-on-action inherent in this process through dialogue, or the potential for reflection to inform actions to be undertaken in the planning phase of the CPD cycle, should not be overlooked by trainee or trainer. Workplace-based assessments offer the trainer a formal means of determining the extent to which their trainee has honed the reflective skills acquired in all aforementioned CPD activities.

Some forms of workplace-based assessments currently in use in the UK lend themselves more to the reflective process than others. Case-based discussion allows the assessor to choose case notes from patients that the trainee has seen and use these as a focus for a discussion of clinical decision-making. The mini-Peer Assessment Tool (mini-PAT) allows peers and colleagues to rate a trainee on a variety of skills, including clinical acumen, teamwork and attitudes. The mini-PAT has the potential to greatly inform trainee reflection-on-action and allows the trainee insight into how their attitudes inform their decision-making.

\section{Implications for patient care}

The ultimate aim of enhancing trainee skills in reflective practice is to improve patient care. One could consider the self-awareness required to identify the processes of transference, countertransference, projection and projective identification inherent in all clinical encounters to be dependent on the process of self-reflection. The context of 
the clinical encounter should not be ignored. Reflection-inaction on how our personal style and issues such as gender, age, culture and ethnicity pervade all patient encounters is essential to biopsychosocial case formulation in psychiatry. Awareness of the potential within patients to generate unexpected reactions within us as treating clinicians should be factored into all diagnostic and treatment decisions. The risk otherwise is that trainees may focus too much on the outcomes and less on the process of the clinical encounter.

\section{Conclusions}

Consultant psychiatrists with responsibility for education, training and competence assurance have a central role to play in promoting reflective practice for junior trainees. The nature and purpose of reflective practice and its assessment must be clear to trainees and supervisors if it is to be incorporated successfully into any CPD programme. Although we have proposed a number of strategies for promoting reflective practice in such a programme, it is likely that many more exist, particularly with the advent of the new basic specialist training curriculum in Ireland. Reflective practice is a continual process of personal development occurring in tandem with, and contributing to, clinical, academic and research skills. There is a growing need to balance the long-standing role of the trainee as a scientific practitioner with an understanding and use of reflective practice. Where there may be a lack of empirical evidence and there is a need to respond creatively to reallife events, the process of reflection can help trainees recognise the part that they as a person, with their own background, feelings, experiences and attitudes, play in all facets of their work as a psychiatrist.

\section{About the authors}

Kieran O'Loughlin is a senior registrar and special lecturer in psychiatry in St Vincent's University Hospital, Dublin. Allys Guerandel is a consultant psychiatrist and senior lecturer in psychiatry in St Vincent's University Hospital, Dublin. Kevin Malone is a professor of psychiatry and consultant psychiatrist at St Vincent's University Hospital, Dublin and University College Dublin.

\section{References}

1 Government of Ireland. Medical Practitioners Act 2007. Government of Ireland, 2007 (http://www.irishstatutebook.ie/2007/en/act/pub/ 0025/index.html).

2 College of Psychiatry of Ireland. Professional Competence for Psychiatrists including CPD and Clinical Audit. College of Psychiatry of Ireland, 2011.

3 Vansteenkiste $M$, Lens W, Deci EL. Intrinsic versus extrinsic goal contents in self-determination theory: another look at the quality of academic motivation. Educ Psychol 2006; 41: 19-31.

4 Schön DA. Educating the Reflective Practitioner. Jossey-Bass, 1987

5 Medical Council of Ireland. Review: Medical Schools in Ireland 2007. Medical Council of Ireland, 2007 (http://www.medicalcouncil.ie/ Media-Centre/Publications/2007/).

6 Watts N, Guerandel A, O'Loughlin K, O'Neill G, Malone K. Promoting reflective writing among psychiatry students. In Proceedings of World Conference on Educational Multimedia, Hypermedia and Telecommunications 2011 (eds T Bastiaens, M Ebner): 884-8. AACE, 2011.

7 Dewey J. Experience and Education. Collier, 1938.

8 Boud D, Keogh R, Walker D. Reflection: Turning Experience into Learning. Kogan Page, 1985.

9 Sandars J. The use of reflection in medical education: AMEE Guide No. 44. Med Teach 2009; 31: 685-95.

10 Moon JA. A Handbook of Reflective Practice and Experiential Learning: Theory and Practice. Routledge Falmer, 2004.

11 Kolb DA. Experiential Learning: Experience as the Source of Learning and Development. Prentice Hall, 1984.

12 Schön DA. The Reflective Practitioner. Temple Smith, 1983.

13 Lavender T. Redressing the balance: the place, history and future of reflective practice in clinical training. Clin Psychol 2003; 27: 11-5.

14 Gantley D. Psychiatrists embrace peer review ahead of the game. Irish Medical Times 2010; 16 June (http://www.imt.ie/opinion/guests/2010/ 06/psychiatrists-embrace-peer-review-ahead-of-the-game.html).

15 Walsh C, Moore A. Peer Review Structure for Consultant Psychiatrists in Ireland. College of Psychiatry of Ireland, 2011 (http://www. irishpsychiatry.ie/Libraries/PCS_Documents/Peer_Review_Group_ Guidelines_V7_-_May_11.sflb.ashx).

16 Krentler KA. Does technology enhance actual student learning? The case of online discussion boards. J Educ Bus 2005; 80: 316-21.

17 Omer S, McCarthy G. Reflective practice in psychiatric training: Balint groups. Ir J Psychol Med 2010; 27: 115-6.

18 College of Psychiatry of Ireland. Basic Specialist Training. College of Psychiatry of Ireland, 2010 (http://www.irishpsychiatry.ie/Libraries/ 2010_before_documents/CPsychi_BST_handbook_sept_2010.sflb.ashx).

19 Samuel O. The aims and objectives of balint training. J Balint Soc 1987; 15: $23-5$.

20 Medical Council of Ireland. Professional development. Medical Council of Ireland, 2010 (http://www.medicalcouncil.ie/Professional-Development/). 